Research Article

\title{
Microarray Analysis of Small Extracellular Vesicle-Derived miRNAs Involved in Oxidative Stress of RPE Cells
}

\author{
$\operatorname{Ke~Mao~} \mathbb{D}^{1,2}$ and Xingwei $\mathrm{Wu} \mathbb{D}^{2}$ \\ ${ }^{1}$ Department of Ophthalmology, Renji Hospital, School of Medicine, Shanghai Jiao Tong University, Shanghai, China \\ ${ }^{2}$ Department of Ophthalmology, Shanghai General Hospital, National Clinical Research Center for Eye Diseases, Shanghai Key \\ Laboratory of Ocular Fundus Diseases, Shanghai Engineering Center for Visual Science and Photomedicine, School of Medicine, \\ Shanghai Jiao Tong University, Shanghai, China
}

Correspondence should be addressed to Xingwei Wu; wxweye@sina.com

Received 23 June 2020; Accepted 3 August 2020; Published 28 October 2020

Guest Editor: Bahare Fazeli

Copyright (c) $2020 \mathrm{Ke}$ Mao and Xingwei Wu. This is an open access article distributed under the Creative Commons Attribution License, which permits unrestricted use, distribution, and reproduction in any medium, provided the original work is properly cited.

\begin{abstract}
The aim of this study was to investigate the miRNA profiles of nanosized small extracellular vesicles (sEVs) from human retinal pigment epithelial (RPE) cells under oxidative damage. ARPE-19 cells were cultured with ox-LDL (100 mg/L) or serum-free medium for 48 hours, sEVs were then extracted, and miRNA sequencing was conducted to identify the differentially expressed genes (DEGs) between the 2 groups. RNA sequence results were validated using quantitative real-time PCR. The Gene Ontology (GO) enrichment, Kyoto Encyclopedia of Genes and Genomes pathway, and ingenuity pathway analyses (IPA) were performed for the DEGs. Results revealed that oxidative stress inhibited RPE cell viability and promoted sEV secretion. A total of 877 DEGs from sEVs were identified, of which 272 were downregulated and 605 were upregulated. In total, 66 enriched GO terms showed that the 3 most significant enrichment terms were cellular processes (biological processes), cell (cellular component), and catalytic activity (molecular function). IPA were used to explore DEGs associated with oxidation damage and further construct a miRNA-target regulatory network. This study identified several DEGs from oxidation-stimulated RPE cells, which may act as potential RNA targets for prognosis and diagnosis of RPE degeneration.
\end{abstract}

\section{Introduction}

Oxidative damage is one of the major contributors to retinal degenerative diseases such as age-related macular degeneration (AMD) [1]. AMD is a multifactorial disease in which oxidative stress serves as a key component. The retinal pigment epithelium (RPE) is a highly specialized, polarized epithelium, which is in intimate contact with the outer segments of the photoreceptor and Bruch's membrane [2]. PRE cells are particularly metabolically active, highly oxygenated, and vulnerable to oxidative stress under exposure to photosensitizers such as lipofuscin [3]. Oxidative stress induces cell apoptosis through reactive oxygen species, thereby leading to RPE dysfunction [4].

Exosome refers to one form of extracellular nanometersized vesicle, which mediates multiple extra- and intercellular activities, including cell-cell communication, immune modulation, extracellular matrix turnover, stem cell division/differen- tiation, neovascularization, and cellular waste removal [5]. RPE cells secrete extracellular vesicles (EVs) in response to oxidative stress, resulting in angiogenesis in endothelial cells [6]. Exosomal biological markers CD63 and LAMP2 have been found in the drusen of AMD patients and stressed RPE cells, which suggests that the drusen is initiated by intracellular proteins from RPE cells and becomes extracellular via the exosome [7]. Small extracellular vesicles (sEVs) contain multiple functional molecules such as mRNA, microRNA (miRNA), and proteases. miRNAs are small noncoding RNA molecules, which inhibit several targeting mRNA expressions. Genetic mutations of miRNAs induce pathophysiological and immunological dysfunction in RPE cells. A related study suggested exosomal miRNA variations as predictive biomarkers in AMD disease [8]. Here, we aimed to screen for differentially expressed miRNA profiles in sEVs derived from oxidative stress-stimulated RPE cells and identify potential functional miRNAs, which may be associated with RPE oxidation. 

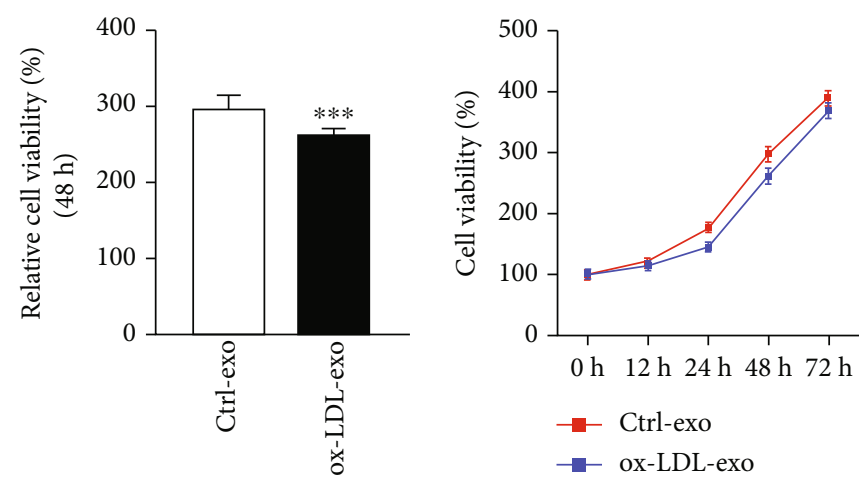

FIGURE 1: ox-LDL reduced RPE cell viability. ARPE-19 cells were treated with control (serum-free medium) or ox-LDL (100 mg/L) for 48 hours. Cell viability was tested by CCK8 assay. Data are expressed as mean $\pm \mathrm{SD}(n=3)$. Experiments were repeated 3 times. ${ }^{* * *} p<0.001$ vs. the control group.
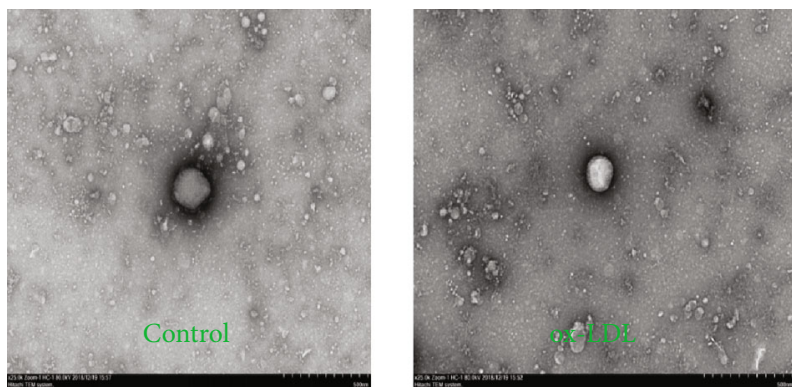

(a)

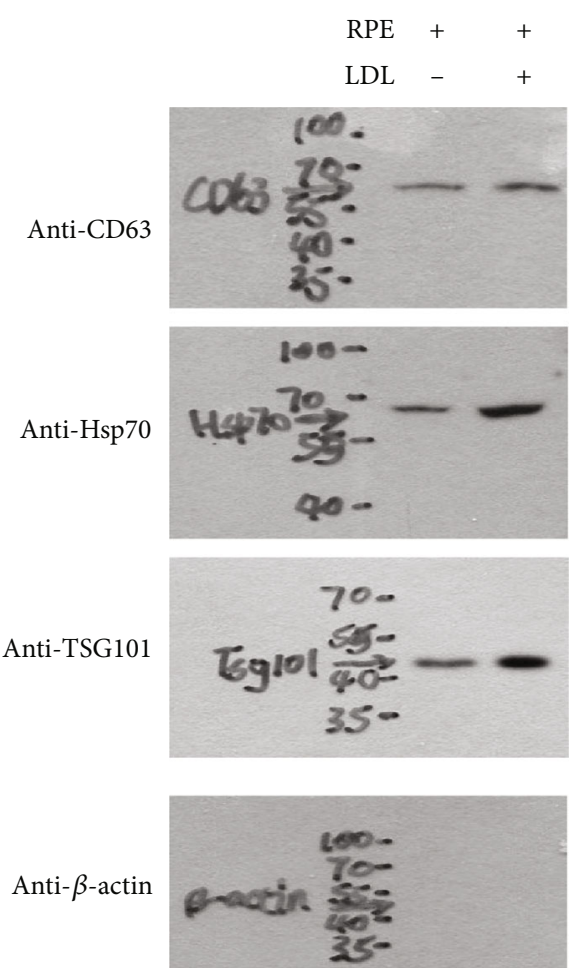

(b)

FIgURE 2: Transmission electron microscopy images of exosome in the ox-LDL and control groups (a) and western blot results of exosomal marker proteins (b).

\section{Materials and Methods}

2.1. Cell Culture and Oxidative Stress Induction. The human RPE cell line (ARPE-19) is transformed and maintained at $1 \times 10^{6}$ cells/mL culture in DMEM/F12 medium (Gibco Life Technologies, Carlsbad, CA, USA) containing 10\% fetal bovine serum (FBS; HyClone, Shanghai, China), penicillin/streptomycin (1:100, Sigma, USA), $4 \mathrm{mM}$ glutamine, and $0.19 \%$ HEPES (Sigma), in a humidified incubator at $37^{\circ} \mathrm{C}$ and $5 \% \mathrm{CO}_{2}$. Cells were seeded and grown to $70-80 \%$ confluence before being placed in a serum-free medium (SFM) for
24 hours, then randomized into SFM or human oxidized low-density lipoprotein (ox-LDL, $100 \mathrm{mg} / \mathrm{L}$, AppliChem, Darmstadt, Germany) groups for 48 hours.

2.2. CCK8 Assay for RPE Cell Viability. ARPE-19 cells were seeded at a density of $1 \times 10^{4}$ cells/100 $\mu \mathrm{L} /$ well in 96 -well plates. After the treatment mentioned above, $10 \mu \mathrm{L}$ of XTT (BBI Life Sciences, China) solution was added into each well for 1 hour at $37^{\circ} \mathrm{C}$. Cell viability was determined by measuring absorbance at $450 \mathrm{~nm}$ using a microplate spectrophotometer (Molecular Devices, Sunnyvale, CA, USA). 


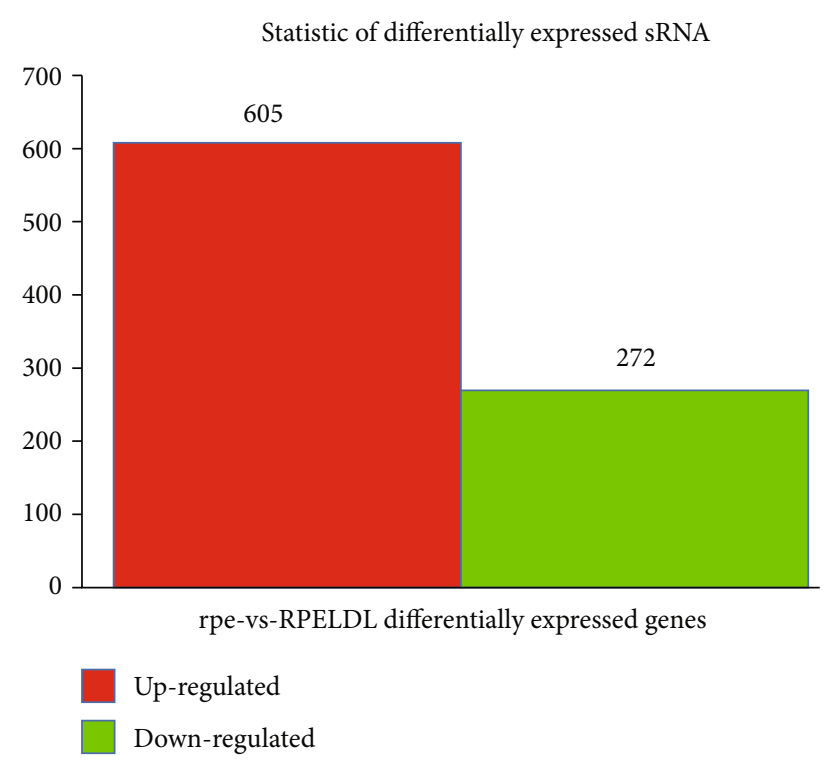

(a)

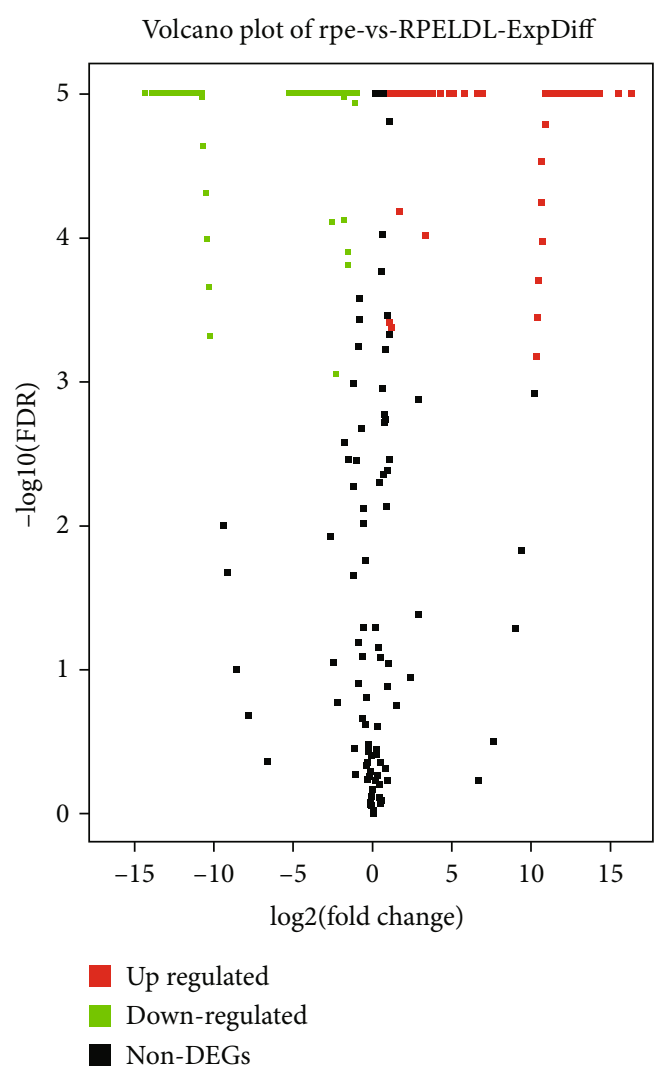

(b)

FIgURE 3: General RNA-Seq analysis of sEV-derived miRNAs and statistical analysis of differentially expressed genes between the ox-LDL and control groups. (a) Histogram of DEGs between 2 groups. (b) Volcano plot of DEGs. $p$ value $<0.05$ was considered significant.

TABLE 1: List of the top 10 DEGs between the ox-LDL and control groups.

\begin{tabular}{|c|c|c|c|c|c|}
\hline Gene ID & log2Ratio (RPELDL/rpe) & $p$ value & FDR & Description & Primer sequence $\left(5^{\prime} \rightarrow 3^{\prime}\right)$ \\
\hline hsa-miR-3184-3p & 16.27193714 & $<0.001$ & $<0.001$ & $\mathrm{Up}$ & ТССТСТТСТСССТССТСССА \\
\hline hsa-let-7e-5p & 15.46467337 & $<0.001$ & $<0.001$ & Up & AGCTGGTGTTGTGAATCAGG \\
\hline hsa-miR-208a-5p & 13.98992663 & $<0.001$ & $<0.001$ & Up & CGCATCCCCTAGGGCATTGG \\
\hline hsa-miR-138-5p & 13.57222651 & $<0.001$ & $<0.001$ & Up & TAGTGCAATATTGCTTATAG \\
\hline hsa-miR-1228-3p & 13.13089227 & $<0.001$ & $<0.001$ & Up & AAAGTCTCGCTCTCTGCCCC \\
\hline hsa-miR-423-5p & -14.52833201 & $<0.001$ & $<0.001$ & Down & GGAGCGAGATCCСТCСАAAAT \\
\hline hsa-miR-1910-5p & -13.02410078 & $<0.001$ & $<0.001$ & Down & GAGCTTTTGGCCCGGGTTAT \\
\hline hsa-miR-197-3p & -11.56985561 & $<0.001$ & $<0.001$ & Down & GGCTGTTGTCATACTTCTCATGG \\
\hline hsa-miR-877-3p & -10.27612441 & $<0.001$ & $<0.001$ & Down & TCACAGTGGCTAAGTTCTGC \\
\hline hsa-miR-324-5p & -9.409390936 & $<0.001$ & $<0.001$ & Down & TGAGGGGCAGAGAGCGAG \\
\hline
\end{tabular}

FDR: false discovery rate.

2.3. Exosome Isolation and Transmission Electron Microscopy Imaging. Exosomes were isolated from ARPE-19 cells using multistep differential centrifugation [9]. ARPE-19 cells were centrifuged at $300 \times \mathrm{g}$ for 10 minutes at $4^{\circ} \mathrm{C}$. Subsequently, the supernatant was subjected to the following centrifugation steps: $2000 \times \mathrm{g}$ for 10 minutes, $10,000 \times \mathrm{g}$ for 30 minutes, and $100,000 \times \mathrm{g}$ for 70 minutes. The resulting sEVs were finally resuspended in PBS and centrifuged at $100,000 \times \mathrm{g}$ for 70 minutes again. The morphology of sEVs was visualized using the Hitachi transmission electron microscope operated at $80 \mathrm{kV}$ (Hitachi, Japan).

2.4. Western Blot Analysis. As described previously [10], after incubating for $5 \mathrm{~min}$ at $90^{\circ} \mathrm{C}$ with loading buffer (Life Technologies, Australia), $10 \mu \mathrm{g}$ of exosomes in each group was electrophoresed on NuPAGE Novex 4-12\% Bis-Tris Gels (Life Technologies, USA). Gels were transferred onto PVDF membranes using the Trans-Blot Turbo system. Membranes 
were blocked in 2\% BSA solution for 3 hours and then probed overnight with primary exosomal marker protein antibodies: anti-Hsp70 (ab134045, Abcam, Cambridge, UK), anti-CD63 (ab181606, Abcam), and anti-TSG101 (ab125011, Abcam) at $4^{\circ} \mathrm{C}$, followed by incubation with a secondary antibody for 3 hours. The ChemiDoc XRS gel documentation system (Bio-Rad Laboratories, USA) was used to quantify the immune-reactive proteins, and $\beta$-actin was used as a loading control for each lane. Each indicated band was quantified and normalized to $\beta$-actin through ImageJ software.

2.5. miRNA Extraction and miRNA Sequencing. As reported previously [11], RNA extraction was performed using the Total Exosome RNA and Protein Isolation Kit (catalog \# 4478545; Invitrogen, USA) according to the provided instructions. $200 \mathrm{ng}-1 \mu \mathrm{g}$ RNA in final volume of $30 \mu \mathrm{L}$ solution was collected for each sample. Total RNA quantity and quality (260/280 absorbance ratio) were assessed using NanoDrop 2000 (Thermo Fisher Scientific, Waltham, MA, USA) and Agilent 2100 Bioanalyzer to test concentration and inorganic ions or polycarbonate contamination. miRNA sequence was isolated by BGI Company (China) based on previous instructions [12]. cDNA libraries were constructed using the Ion Total RNA-Seqv2 kit (Life Technologies, USA) ( $n=3$ for each group) and purified using AMPure beads (Beckman Coulter). Emulsion PCR and enrichment of cDNA-conjugated particles were performed with an Ion OneTouch 200 Template Kit v2 DL (Life Technologies). The final cDNA samples were sequenced single end on the HiSeq 2000 System with a 50 bp read length.

2.6. Bioinformatics Analysis of the Data. Raw data was filtered to eliminate low-quality reads, primers, adaptors, and other contaminants. Following this, we summarized the length distribution and common and specific sequences between samples. After filtering, the remaining tags were called clean tags and stored in FASTQ format. Bowtie2 was used to map clean reads to the reference genome and other sRNA databases. To identify differentially expressed genes (DEGs), differentially expressed miRNAs (DEMIs) were screened out using the limma package through the thresholds of fold change $>2$ or $<0.5$ and adjusted $p$ value of $<0.05$ [13].

To perform Gene Ontology (GO) enrichment analysis, we mapped all genes to GO terms in the database, which calculated the gene numbers for every term. The hypergeometric test was then used to find significantly enriched GO terms in the input gene list.

The Kyoto Encyclopedia of Genes and Genomes (KEGG) pathway was used to perform pathway enrichment analysis. This analysis identified significantly enriched metabolic or signal transduction pathways from target genes of DEGs when compared with the whole genome background. The $p$ value was corrected using the Bonferroni method; a corrected $p$ value $<0.05$ was considered significant.

In this study, experimentally verified miRNA-mRNA regulatory pairs were obtained using TargetScan and miRanda and a miRNA-target regulatory network was constructed by comparing the DEGs with obtained miRNA-gene regulatory pairs.
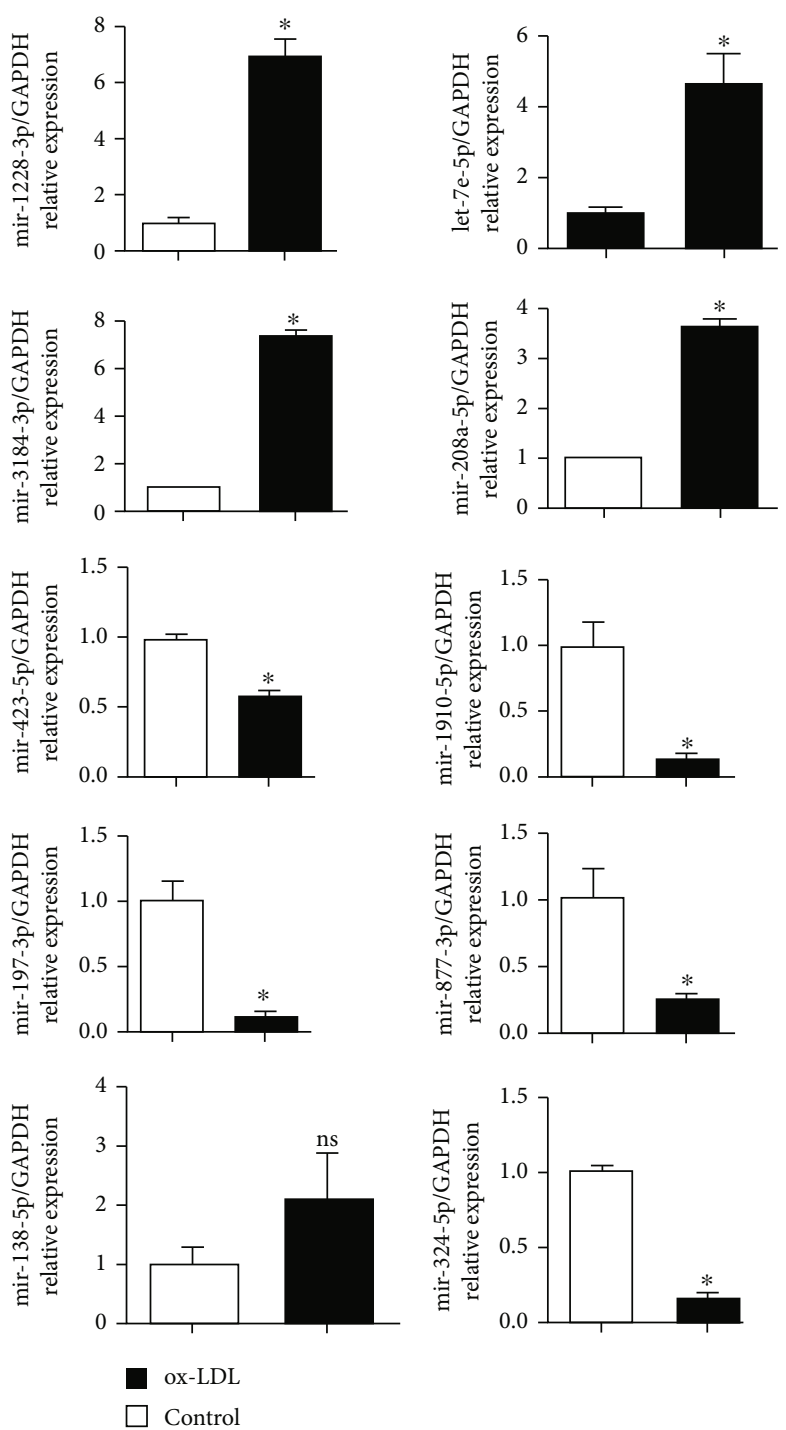

FIgURE 4: Validation of the top 10 selected DEGs screened from miRNA sequence by qRT-PCR tests. ARPE-19 cells were treated as before, and miRNAs were extracted from sEVs. Data was expressed as mean $\pm \mathrm{SD}(n=6)$. Experiments were repeated three times. ${ }^{*} p<0.05$ vs. the control group. ns: no significance.

2.7. Validation of miRNA Expression Using Quantitative Real-Time PCR (RT-PCR). In order to validate initial miRNA sequence results, the 10 most significant up- or downregulated miRNAs were selected for further RT-PCR tests as reported previously [14]. Total RNA was isolated using TRIzol reagent and the quality and quantity of RNA was measured using a NanoDrop 2000 spectrophotometer. Each reverse transcription reaction mixture contained $10 \mathrm{~mL}$ of SYBR Green Master Mix, $0.5 \mathrm{~mL}$ of miR-RT primers $\mathrm{F}$ $(10 \mathrm{mM}), \quad 0.5 \mathrm{~mL}$ of miR-RT primers $\mathrm{R}(10 \mathrm{mM})$, and RNase-free $\mathrm{H}_{2} \mathrm{O}$. The RT-PCR reactions for the selected 10 miRNAs were performed using the ViiA 7 Real-Time PCR System (ABI, USA) under the following conditions: $95^{\circ} \mathrm{C}$ for $1 \mathrm{~min}$, followed by $40 \mathrm{PCR}$ cycles $\left(95^{\circ} \mathrm{C}\right.$ for $10 \mathrm{~s}$ and then $60^{\circ} \mathrm{C}$ for $20 \mathrm{~s}$ ). miRNA expression was normalized to the endogenous reference gene GAPDH. Each sample was 


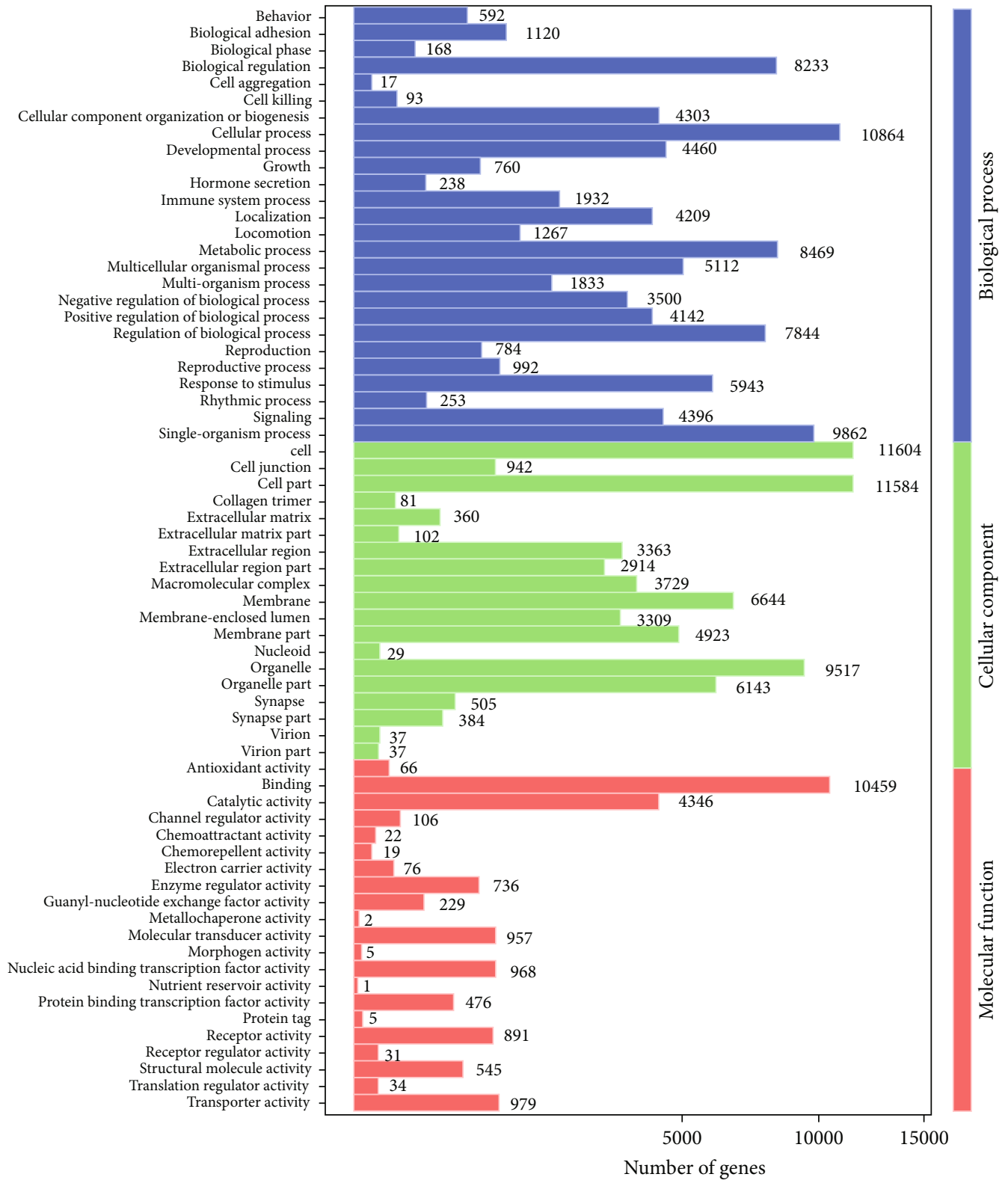

FIGURE 5: Go enrichment analysis of DEGs between 2 groups. Blue, green, and red bars represent the enrichment and numbers of DEGs in the biological process, cellular component, and molecular function, respectively.

analyzed in triplicate. Specific primers were produced by BIOTNT Company (Shanghai, China). Relative quantification was achieved by the comparative $2^{-\Delta \Delta \text { ct }}$ method.

2.8. Statistics. The data were analyzed with a one-way analysis of variance (ANOVA) using the statistical program SPSS 17.0. All data were presented as mean \pm SD. $p$ value $<0.05$ was considered statistically significant.

\section{Results}

3.1. ox-LDL Decreases ARPE-19 Cell Viability. We first measured the cytotoxicity of ox-LDL to ARPE-19 cells after 48 hours. Figure 1 shows that cell viability in the ox-LDL group was significantly lower than that in the control group $(p<0.05)$, which indicated its cytotoxicity and aligned with previous conclusions $[15,16]$.

\subsection{Characterization of $s E V s$ and Biological Marker Protein} Detection. Transmission electron microscopy images of sEVs derived from both groups revealed the presence of distinct vesicles with an average diameter of $106 \pm 7.62 \mathrm{~nm}$ (Figure 2(a)). The vesicles were also positive for exosomal markers. CD63 is the general tetraspanin protein used as the exosomal "star marker" [17]. TSG101 and Hsp70 are also commonly used for exosome detection $[18,19]$. As shown in Figure 2(b), we found that the expression levels of TSG101 and Hsp70 were statistically higher in the ox-LDL group than the control, but it did not reach a significant difference $(p>0.05)$. 


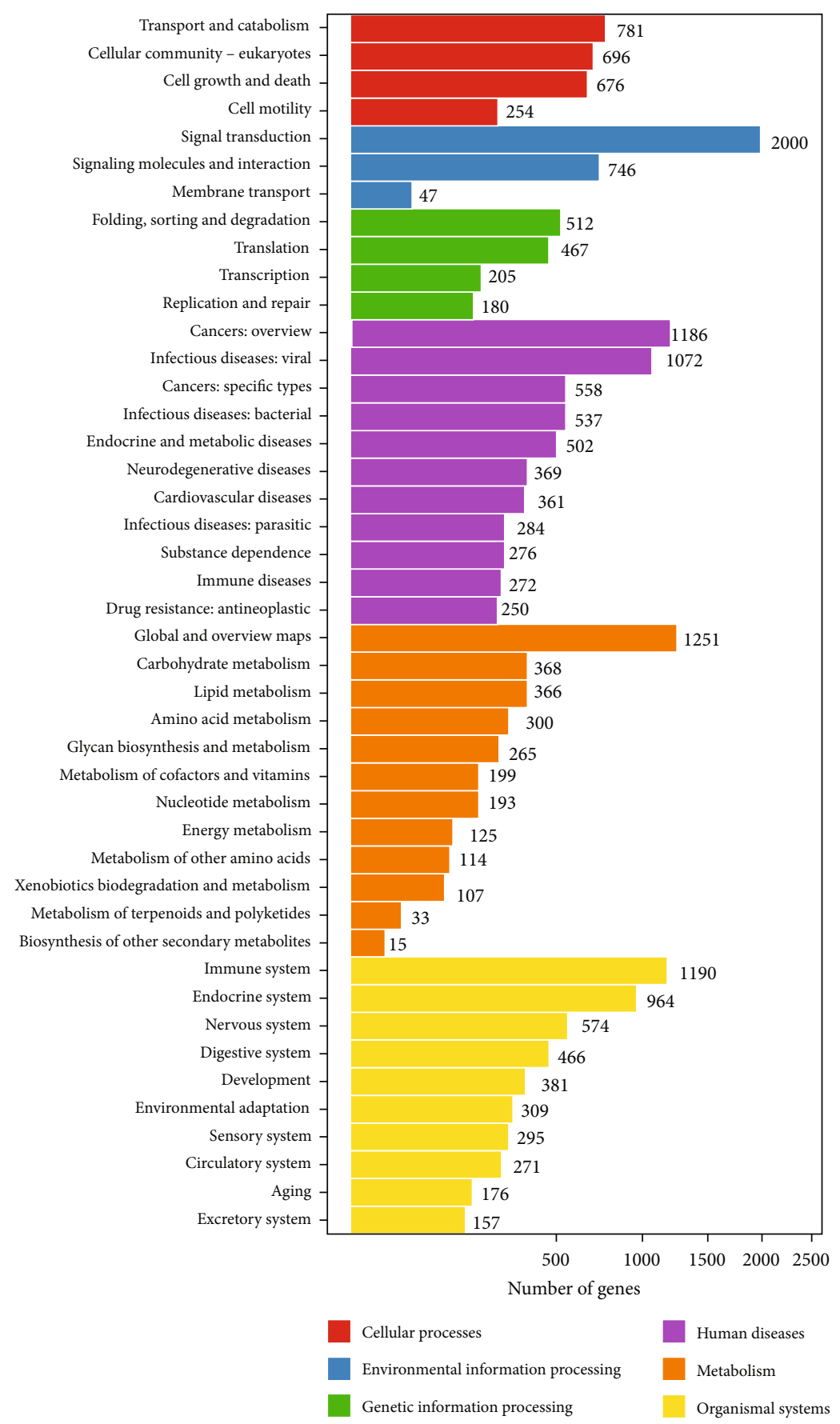

(a)

Figure 6: Continued. 


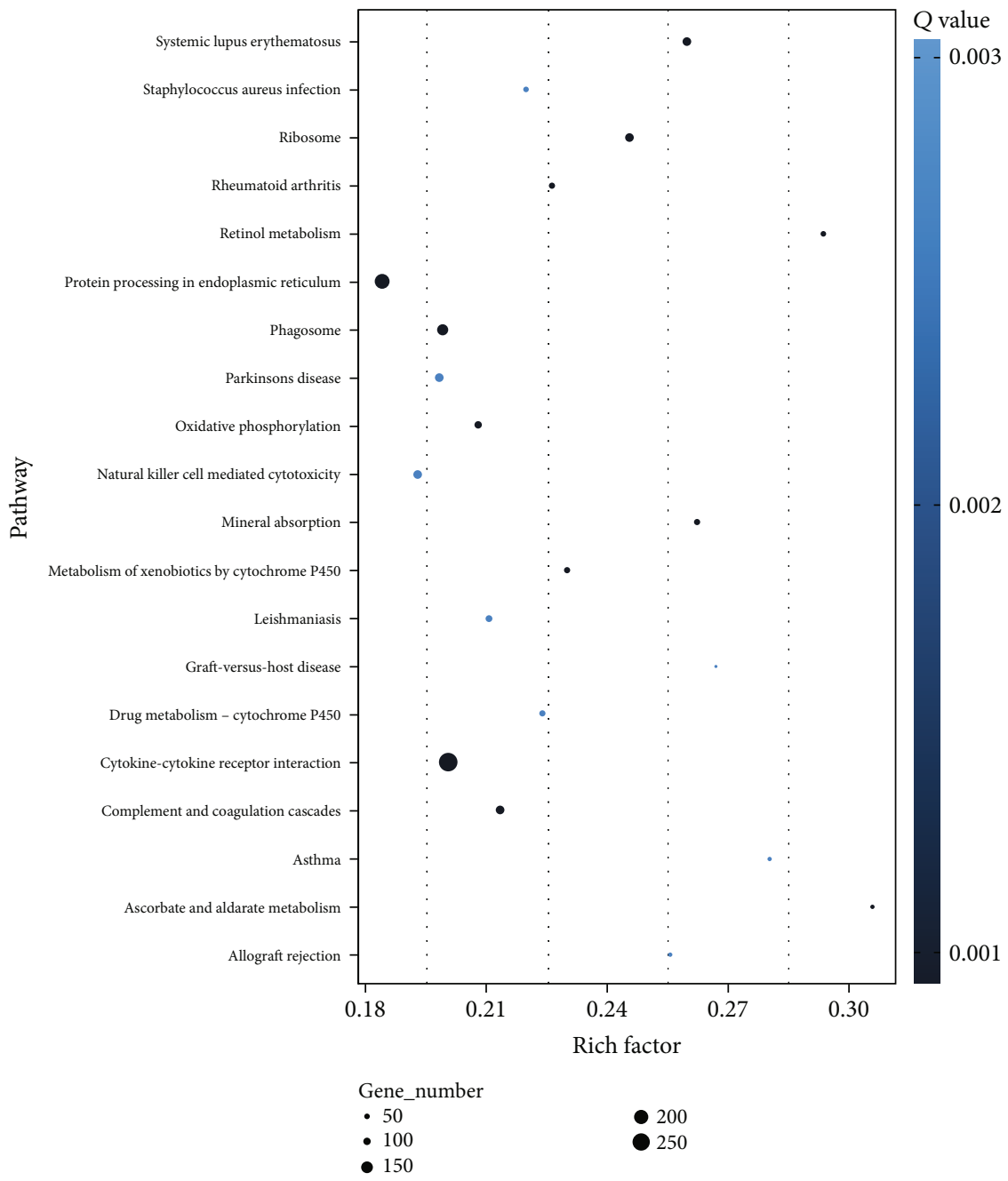

(b)

FIGURE 6: KEGG pathways analysis of DEGs between 2 groups. (a) 6 categories of biological functions and numbers of genes in different pathways. (b) Rich factors of the 20 most enriched pathways. The sizes of circles correspond to gene numbers. The colors correspond to the $Q$ value.

3.3. Differential Expression of miRNA Profiles in $s E V$ s Isolated from the Oxidative and Control RPE Cells. In order to identify the influence of oxidation on miRNA profiles from sEVs of RPE cells, miRNA sequence was sequenced after treatment for 48 hours. Figure 3 shows that 877 significantly differentially expressed miRNAs had been screened between the ox-LDL and control groups, among which 272 were downregulated and 605 were upregulated. The top 10 differentially expressed genes are listed in Table 1.

3.4. DEG Validation Using RT-PCR. The top 10 selected DEGs were further validated using RT-PCR (Figure 4). PCR tests revealed similar results of RNA sequence, except that miR-138-5p showed insignificant differences between the two groups $(p>0.05)$.

3.5. Gene Ontology Enrichment Analysis. The GO analysis contains three ontologies: biological processes, molecular function, and cellular components. We identified 66 enriched
GO terms, among which 26 belong to biological processes, 21 belong to molecular function, and 19 belong to cellular components. The three most enriched biological process terms were cellular processes, single-organism processes, and metabolic processes. Meanwhile, cell, cell part, organelle, catalytic activity, transporter activity, and transporter activity were the most enriched GO terms of cellular components and molecular function, respectively (Figure 5).

3.6. KEGG Pathway Enrichment Analysis. KEGG analysis classified DEGs into 6 categories according to their biological functions: cellular processes (4 pathways), environmental information processing (3 pathways), genetic information processing (4 pathways), human diseases (11 pathways), metabolism (12 pathways), and organismal systems (10 pathways). The 20 most enriched pathways are presented in Figure 6.

3.7. Functional Exploration with Ingenuity Pathway Analysis. Based on the KEGG and Gene Ontology results, we further 
TABLE 2: List of DEGs in IPA.

\begin{tabular}{|c|c|c|c|c|}
\hline Function & $\begin{array}{l}\text { Pathway or } \\
\text { GOID }\end{array}$ & Name (Homo sapiens (human)) & Count & Gene ID \\
\hline \multirow{6}{*}{ AMD } & hsa02010 & $\mathrm{ABC}$ transporters & 8 & $\begin{array}{l}\text { miR-345-5p, miR-210-5p, miR-34a-5p, miR-1908-5p, miR-485- } \\
\text { 5p, miR-1343-3p, miR-423-5p, miR-4488 }\end{array}$ \\
\hline & hsa03420 & Nucleotide excision repair & 5 & $\begin{array}{l}\text { miR-138-5p, miR-345-5p, miR-1908-5p, miR-1343-3p, miR- } \\
485-5 p\end{array}$ \\
\hline & hsa04060 & $\begin{array}{l}\text { Cytokine-cytokine receptor } \\
\text { interaction }\end{array}$ & 12 & $\begin{array}{l}\operatorname{miR}-138-5 p, \operatorname{miR}-345-5 p, \operatorname{miR}-210-5 p, \operatorname{miR}-378 a-5 p, \text { miR-34a- } \\
\text { 5p, miR-1908-5p, miR-1343-3p, miR-485-5p, miR-423-5p, miR- } \\
\text { 4488, miR-210-5p, miR-423-5p }\end{array}$ \\
\hline & hsa04062 & Chemokine signaling pathway & 9 & $\begin{array}{l}\text { miR-138-5p, miR-345-5p, miR-210-5p, miR-378a-5p, miR- } \\
\text { 1908-5p, miR-1343-3p, miR-485-5p, miR-423-5p, miR-4488 }\end{array}$ \\
\hline & hsa04145 & Phagosome & 7 & $\begin{array}{l}\text { miR-138-5p, miR-210-5p, miR-1908-5p, miR-1343-3p, miR- } \\
\text { 485-5p, miR-423-5p, miR-4488 }\end{array}$ \\
\hline & hsa04620 & $\begin{array}{l}\text { Toll-like receptor signaling } \\
\text { pathway }\end{array}$ & 6 & $\begin{array}{l}\text { miR-345-5p, miR-210-5p, miR-1908-5p, miR-1343-3p, miR- } \\
\text { 485-5p, miR-4488 }\end{array}$ \\
\hline \multirow{4}{*}{$\begin{array}{l}\text { Lipid } \\
\text { metabolism }\end{array}$} & hsa00561 & Glycerolipid metabolism & 10 & $\begin{array}{l}\text { miR-138-5p, miR-345-5p, miR-378a-5p, miR-34a-5p, miR- } \\
\text { 1908-5p, miR-1343-3p, miR-485-5p, miR-423-5p, miR-4488, } \\
\text { miR-210-5p }\end{array}$ \\
\hline & hsa00564 & Glycerophospholipid metabolism & 10 & $\begin{array}{l}\text { miR-138-5p, miR-345-5p, miR-210-5p, miR-378a-5p, miR-34a- } \\
\text { 5p, miR-1908-5p, miR-1343-3p, miR-485-5p, miR-423-5p, miR- } \\
4488\end{array}$ \\
\hline & hsa00565 & Ether lipid metabolism & 3 & miR-34a-5p, miR-423-5p, miR-4488 \\
\hline & hsa00600 & Sphingolipid metabolism & 6 & $\begin{array}{l}\text { miR-34a-5p, miR-1908-5p, miR-1343-3p, miR-485-5p, miR- } \\
\text { 423-5p, miR-4488 }\end{array}$ \\
\hline \multirow{5}{*}{$\begin{array}{l}\text { Oxidative } \\
\text { damage }\end{array}$} & GO:1902175 & $\begin{array}{l}\text { Regulation of oxidative stress- } \\
\text { induced intrinsic apoptotic } \\
\text { signaling pathway }\end{array}$ & 0 & \\
\hline & GO:1900407 & $\begin{array}{l}\text { Regulation of cellular response to } \\
\text { oxidative stress }\end{array}$ & 9 & $\begin{array}{l}\text { miR-138-5p, miR-345-5p, miR-210-5p, miR-34a-5p, miR-1908- } \\
\text { 5p, miR-1343-3p, miR-485-5p, miR-423-5p, miR-4488 }\end{array}$ \\
\hline & GO:0001306 & $\begin{array}{l}\text { Age-dependent response to } \\
\text { oxidative stress }\end{array}$ & 9 & $\begin{array}{l}\text { miR-138-5p, miR-345-5p, miR-210-5p, miR-34a-5p, miR-1908- } \\
\text { 5p, miR-1343-3p, miR-485-5p, miR-423-5p, miR-4488 }\end{array}$ \\
\hline & GO:0036473 & $\begin{array}{l}\text { Cell death in response to oxidative } \\
\text { stress }\end{array}$ & 4 & miR-138-5p, miR-210-5p, miR-1343-3p, miR-4488 \\
\hline & GO:1902882 & $\begin{array}{l}\text { Regulation of response to oxidative } \\
\text { stress }\end{array}$ & 9 & $\begin{array}{l}\text { miR-138-5p, miR-345-5p, miR-210-5p, miR-34a-5p, miR-1908- } \\
\text { 5p, miR-1343-3p, miR-485-5p, miR-423-5p, miR-4488 }\end{array}$ \\
\hline \multirow{5}{*}{$\begin{array}{l}\text { Cellular } \\
\text { inflammation }\end{array}$} & GO:0002532 & $\begin{array}{l}\text { Production of molecular mediator } \\
\text { involved in inflammatory response }\end{array}$ & 8 & $\begin{array}{l}\text { miR-4488, miR-345-5p, miR-378a-5p, miR-34a-5p, miR-1908- } \\
\text { 5p, miR-1343-3p, miR-485-5p, miR-423-5p }\end{array}$ \\
\hline & GO:0002534 & $\begin{array}{l}\text { Cytokine production involved in } \\
\text { inflammatory response }\end{array}$ & 8 & $\begin{array}{l}\text { miR-4488, miR-345-5p, miR-378a-5p, miR-34a-5p, miR-1908- } \\
\text { 5p, miR-1343-3p, miR-485-5p, miR-423-5p }\end{array}$ \\
\hline & GO:0002537 & $\begin{array}{l}\text { Nitric oxide production involved in } \\
\text { inflammatory response }\end{array}$ & 0 & \\
\hline & GO:0002540 & $\begin{array}{l}\text { Leukotriene production involved } \\
\text { in inflammatory response }\end{array}$ & 0 & \\
\hline & GO:0002541 & $\begin{array}{l}\text { Activation of plasma proteins } \\
\text { involved in acute inflammatory } \\
\text { response }\end{array}$ & 0 & \\
\hline $\begin{array}{l}\text { Choroid } \\
\text { angiogenesis }\end{array}$ & GO:0045765 & Regulation of angiogenesis & 7 & $\begin{array}{l}\operatorname{miR}-4488, \text { miR-138-5p, miR-345-5p, miR-210-5p, miR-1908- } \\
\text { 5p, miR-1343-3p, miR-423-5p }\end{array}$ \\
\hline
\end{tabular}

searched for related functional genes and associated pathways by ingenuity pathway analysis (IPA) from DEGs. We identified several pathways and genes which related to AMD (6 pathways), lipid metabolism (4 pathways), oxidative damage (5 GO terms), cellular inflammation (5 GO terms), and choroidal neovascularization (GO:0045765) (Table 2).
3.8. miRNA-Target Regulatory Network Analysis. We used TargetScan and miRanda software to predict possible targeted mRNAs for DEGs and associated their intersections with the IPA results; a total of 10 miRNAs and 43 targeted mRNAs formed a miRNA-target regulatory network (Figure 7). 


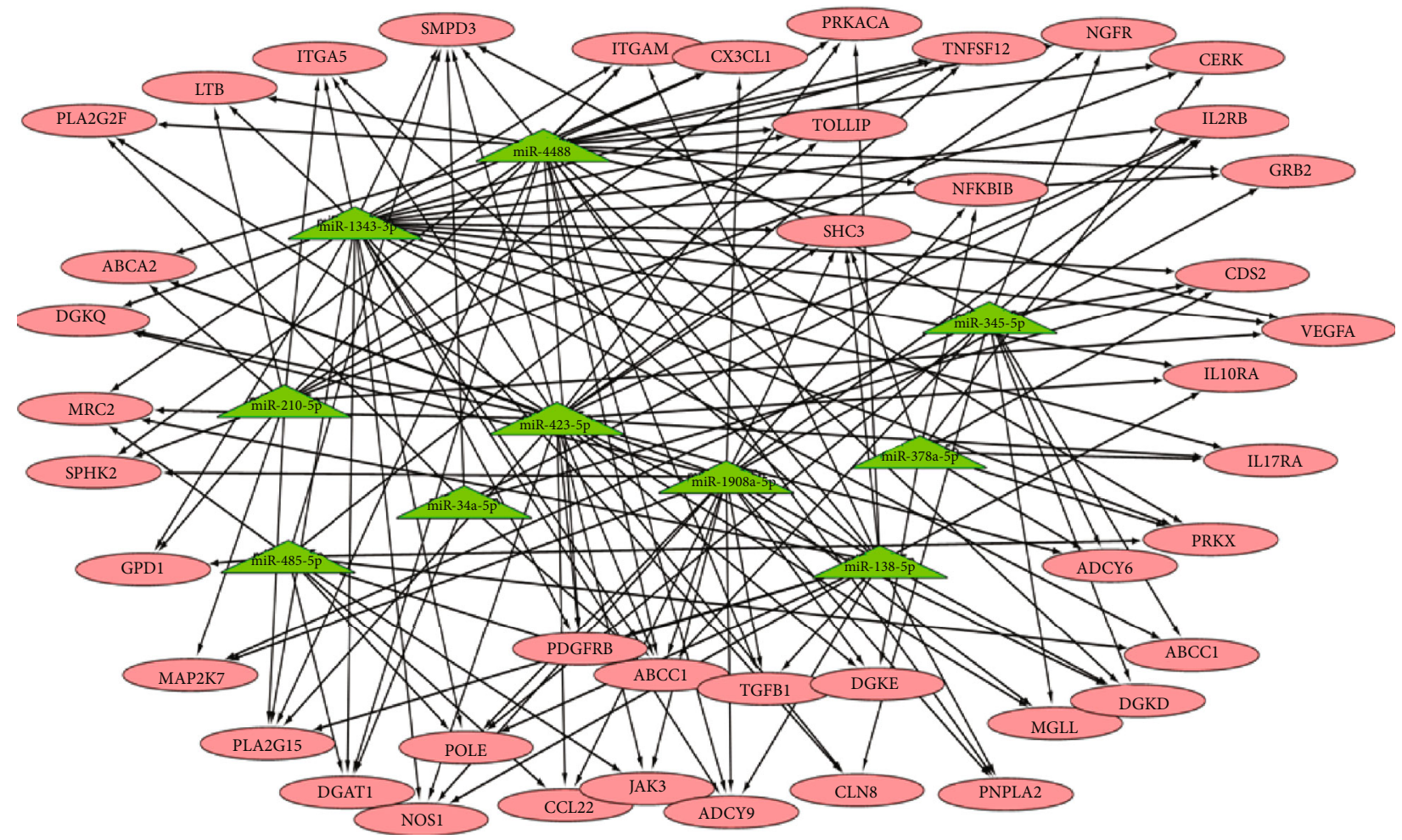

FIGURE 7: microRNA-target regulatory networks of differentially expressed genes (DEGs). Green triangles represent miRNAs; red circles represent targeting genes.

TABLE 3: List of DEGs related to AMD in previous studies.

\begin{tabular}{lcccc}
\hline Gene ID & log2Ratio (RPELDL/rpe) & $p$ value & FDR & Description \\
\hline hsa-miR-192 [12] & -10.98 & $<0.001$ & $<0.001$ & Down \\
hsa-let-7c [25] & 5.60 & $<0.001$ & $<0.001$ & Up \\
hsa-miR-183 [24] & 12.16 & $<0.001$ & $<0.001$ & Up \\
hsa-miR-27a [25, 26] & 12.10 & $<0.001$ & $<0.001$ & Up \\
hsa-miR-27b [22] & 4.99 & $<0.001$ & $<0.001$ & Up \\
hsa-miR-361-5p [12] & -11.94 & $<0.001$ & $<0.001$ & Down \\
hsa-miR-335 [12,22] & -12.06 & $<0.001$ & $<0.001$ & Down \\
hsa-miR-30c [25] & 10.51 & $<0.001$ & $<0.001$ & Up \\
\hline
\end{tabular}

\section{Discussion}

Oxidative stress has been recognized as a major influence in AMD pathophysiology, and RPE appears to be the main site of damage [2]. Oxidative damage of the RPE layer originates from the digestion of photoreceptor outer segments and other reactive oxygen species. RPE damage occurs in multiple locations within the central part of the eye and finally forms a region of atrophy by the bystander effect, which is mediated via EVs [20]. In this research, ox-LDL decreased ARPE-19 cell viability and promoted sEV secretion. RNA sequences and RT-PCR tests confirmed a downregulation of $m i R-1910-5 p$ in sEVs of the ox-LDL group, which is contrary to a similar study that found that $\mathrm{H}_{2} \mathrm{O}_{2}$ increases miR-1910-5p concentrations in ARPE-19 cells [21]. $m i R-324-5 p$ was reported to be expressed in plasma of wet AMD patients, and we found a decreased expression in the ox-LDL group [22]. Desjarlais et al. [23] demonstrated an upregulation of let$7 g-5 p(>570 \%)$ in oxygen-induced retinopathy models during the neovascularization phase, which is consistent with our result. Other authors reported significant changes of miR-192, let-7c, miR-183, miR-27a, miR-27b, miR-361-5p, $m i R-335$, and $m i R-30 c$ in experimental AMD models, which were also observed in our study (see Table 3) [24-26]. KEGG analysis suggested cytokine-cytokine receptor interactions and phagosome and protein processing in the endoplasmic reticulum to be the most significant enrichment items. In agreement with other reports, cancer-related pathways are also involved in DEGs of sEVs in our study [15]. Further research is needed to explore the specific roles of these pathways.

IPA screened out 6 key pathways related to AMD and 4 GO terms related to oxidative damage. $m i R-138-5 p$, $m i R$ - 
345-5p, miR-210-5p, miR-34a-5p, miR-1908-5p, miR-1343$3 p, m i R-485-5 p, m i R-423-5 p$, and $m i R-4488$ are associated with oxidative stress and AMD.

The miRNA-target regulatory network consists of several miRNAs and predicted targeting mRNAs. miR1343 was proved to be activated in response to stress in epithelial cells and targets both TGF- $\beta$ receptors, which in turn contribute to the progression of angiogenesis in wet AMD [27, 28]. $m i R-4488$ was demonstrated to be involved in sphingolipid signaling and to modulate endoplasmic reticulum stress marker PERK in ARPE-19 cells [29]. miR-345-5p was found to be downregulated in ARPE-19 cells undergoing oxidative stress, which is also consistent with our findings [21]. A $m i R-210-5 p$ variant was demonstrated to affect $C F B$ expression in RPE cells and modulate the $C F B$ level in AMD patients [30]. $m i R-423-5 p$ is significantly increased in the proliferative diabetic retinopathy eyes and believed to modulate angiogenic signals [31]. In this study, it was downregulated Iafter ox-LDL treatment $(\mathrm{FC}=-14.52, p<0.05)$. miR-1908$5 p$ plays an important role in regulating lipid metabolism in blood, and $m i R-378 a-5 p / 138-5 p / 34 a-5 p$ are important miRNAs mediating lipid metabolism, tumor angiogenesis, and oxidative stress [32-36]. According to the IPA results, miRNA-target mRNA network, and previous references, miR-138-5p, miR-345-5p, miR-210-5p, miR-34a-5p, miR1908-5p, $m i R-1343-3 p, m i R-485-5 p, m i R-423-5 p$, and $m i R-$ 4488 may serve as potential RNA targets for prognosis and diagnosis of RPE degeneration.

Compared with previous attempts at this type of analysis, a lower number of identified DEGs coincided with this study, which is probably due to the use of different oxidative injury models in RPE cells. Our research investigated acute responses of RPE cells to oxidative stress, which could not represent pathogenesis of AMD since it is a long-term effect.

\section{Conclusion}

n conclusion, exploring oxidative stress-induced miRNA profiles has led us to potential prospects in evaluating RNA variation in sEVs, which may be useful as prognostic and diagnostic tools in the future.

\section{Abbreviations}

sEVs: $\quad$ Small extracellular vesicles

RPE: Retinal pigment epithelium

ox-LDL: Oxidized low-density lipoprotein

SFM: $\quad$ Serum-free medium

DEGs: Differentially expressed genes

GO: $\quad$ Gene Ontology

KEGG: Kyoto Encyclopedia of Genes and Genomes

IPA: Ingenuity pathway analyses

AMD: Age-related macular degeneration.

\section{Data Availability}

The data that support the findings of this study are available from the corresponding author upon reasonable request.

\section{Conflicts of Interest}

The authors report no conflicts of interest.

\section{Authors' Contributions}

Professor Xingwei Wu conceived the study, participated in its design and coordination, and helped draft the manuscript. Dr. Ke Mao participated in the design and operation of this experiment, performed the statistical analysis, and drafted the manuscript. All authors have read and approved the final manuscript.

\section{Acknowledgments}

This work was supported by the National Natural Science Foundation of China (No. 81674027).

\section{References}

[1] S. Han, J. Chen, J. Hua et al., "MITF protects against oxidative damage-induced retinal degeneration by regulating the NRF2 pathway in the retinal pigment epithelium," Redox Biology, vol. 34, article 101537, 2020.

[2] S. Datta, M. Cano, K. Ebrahimi, L. Wang, and J. T. Handa, "The impact of oxidative stress and inflammation on RPE degeneration in non-neovascular AMD," Progress in Retinal and Eye Research, vol. 60, pp. 201-218, 2017.

[3] M. Ji Cho, S. J. Yoon, W. Kim et al., "Oxidative stress-mediated TXNIP loss causes RPE dysfunction," Experimental \& Molecular Medicine, vol. 51, no. 10, pp. 1-13, 2019.

[4] S. Beatty, H. Koh, M. Phil, D. Henson, and M. Boulton, "The role of oxidative stress in the pathogenesis of age-related macular degeneration," Survey of Ophthalmology, vol. 45, no. 2, pp. 115-134, 2000.

[5] M. Klingeborn, W. M. Dismuke, C. Bowes Rickman, and W. D. Stamer, "Roles of exosomes in the normal and diseased eye," Progress in Retinal and Eye Research, vol. 59, pp. 158177, 2017.

[6] Y. Tong, Y. L. Zhou, Y. X. Wang, P. Q. Zhao, and Z. Y. Wang, "Retinal pigment epithelium cell-derived exosomes: possible relevance to $\mathrm{CNV}$ in wet-age related macular degeneration," Medical Hypotheses, vol. 97, pp. 98-101, 2016.

[7] A. L. Wang, T. J. Lukas, M. Yuan, N. Du, M. O. Tso, and A. H. Neufeld, "Autophagy and exosomes in the aged retinal pigment epithelium: possible relevance to Drusen Formation and age-related macular degeneration," PLoS One, vol. 4, no. 1, article e4160, 2009.

[8] H. Elshelmani and S. Rani, "Exosomal microRNA discovery in age-related macular degeneration," Methods in Molecular Biology, vol. 1509, pp. 93-113, 2017.

[9] C. Lässer, M. Eldh, and J. Lötvall, "Isolation and characterization of RNA-containing exosomes," Journal of Visualized Experiments, vol. 9, no. 59, article e3037, 2012.

[10] IY. Q. Koh, F. B. Almughlliq, K. Vaswani, H. N. Peiris, and M. D. Mitchell, "Exosome enrichment by ultracentrifugation and size exclusion chromatography," Frontiers in Bioscience, vol. 23, no. 3, pp. 865-874, 2018.

[11] K. Elmasry, R. Mohamed, I. Sharma et al., "Epigenetic modifications in hyperhomocysteinemia: potential role in diabetic 
retinopathy and age-related macular degeneration," Oncotarget, vol. 9, no. 16, pp. 12562-12590, 2018.

[12] F. Grassmann, P. G. A. Schoenberger, C. Brandl et al., "A circulating microrna profile is associated with late-stage neovascular age-related Macular Degeneration," PLoS One, vol. 9, no. 9, article e107461, 2014.

[13] W. Zhang, S. Han, and K. Sun, "Combined analysis of gene expression, miRNA expression and DNA methylation profiles of osteosarcoma," Oncology Reports, vol. 37, no. 2, pp. 11751181, 2017.

[14] A. Elbay, Ç. Ercan, F. Akbaş, H. Bulut, and H. Ozdemir, "Three new circulating microRNAs may be associated with wet agerelated macular degeneration," Scandinavian Journal of Clinical and Laboratory Investigation, vol. 79, no. 6, pp. 388-394, 2019.

[15] M. Oltra, L. Vidal-Gil, R. Maisto et al., "miR302a and 122 are deregulated in small extracellular vesicles from ARPE-19 cells cultured with $\mathrm{H}_{2} \mathrm{O}_{2}$," Scientific Reports, vol. 9, no. 1, article 17954, 2019.

[16] R. Maisto, M. Oltra, L. Vidal-Gil et al., "ARPE-19-derived VEGF-containing exosomes promote neovascularization in HUVEC: the role of the melanocortin receptor 5," Cell Cycle, vol. 18, no. 4, pp. 413-424, 2019.

[17] C. Zhu, L. Li, Z. Wang, M. Irfan, and F. Qu, "Recent advances of aptasensors for exosomes detection," Biosensors \& Bioelectronics, vol. 160, p. 112213, 2020.

[18] J. M. Street, E. H. Koritzinsky, D. M. Glispie, and P. S. T. Yuen, "Urine exosome isolation and characterization," Methods in Molecular Biology, vol. 1641, pp. 413-423, 2017.

[19] J. Kowal, G. Arras, M. Colombo et al., "Proteomic comparison defines novel markers to characterize heterogeneous populations of extracellular vesicle subtypes," Proceedings of the National Academy of Sciences of the United States of America, vol. 113, no. 8, pp. E968-E977, 2016.

[20] N. Shah, M. Ishii, C. Brandon et al., "Extracellular vesiclemediated long-range communication in stressed retinal pigment epithelial cell monolayers," Biochimica et Biophysica Acta (BBA) - Molecular Basis of Disease, vol. 1864, no. 8, pp. 2610-2622, 2018.

[21] L. Ayaz and E. Dinç, "Evaluation of microRNA responses in ARPE-19 cells against the oxidative stress," Cutaneous and Ocular Toxicology, vol. 37, no. 2, pp. 121-126, 2017.

[22] S. Ertekin, O. Yıldırım, E. Dinç, L. Ayaz, S. B. Fidancı, and L. Tamer, "Evaluation of circulating miRNAs in wet agerelated macular degeneration," Molecular Vision, vol. 20, pp. 1057-1066, 2014.

[23] M. Desjarlais, J. C. Rivera, I. Lahaie et al., "MicroRNA expression profile in retina and choroid in oxygen-induced retinopathy model," PLoS One, vol. 14, no. 6, article e0218282, 2019.

[24] M. Karali, M. Persico, M. Mutarelli et al., "High-resolution analysis of the human retina miRNome reveals isomiR variations and novel microRNAs," Nucleic Acids Research, vol. 44, no. 4, pp. 1525-1540, 2016.

[25] C. Ren, Q. Liu, Q. Wei et al., "Circulating miRNAs as potential biomarkers of age-related macular degeneration," Cellular Physiology and Biochemistry, vol. 41, no. 4, pp. 1413-1423, 2017.

[26] M. Szemraj, A. Bielecka-Kowalska, K. Oszajca et al., "Serum microRNAs as potential biomarkers of AMD," Medical Science Monitor, vol. 21, pp. 2734-2742, 2015.
[27] L. R. Stolzenburg, S. Wachtel, H. Dang, and A. Harris, "miR1343 attenuates pathways of fibrosis by targeting the TGF- $\beta$ receptors," The Biochemical Journal, vol. 473, no. 3, pp. 245256, 2016.

[28] K. Wang, H. Li, R. Sun et al., "Emerging roles of transforming growth factor $\beta$ signaling in wet age-related macular degeneration," Acta Biochimica et Biophysica Sinica, vol. 51, no. 1, pp. 1-8, 2019.

[29] S. Arumugam, B. Mary, M. Kumar, and G. R. Jayandharan, "Analysis of hepatic and retinal cell microRNAome during AAV infection reveals their diverse impact on viral transduction and cellular physiology," Gene, vol. 724, article 144157, 2020.

[30] M. Ghanbari, S. J. Erkeland, L. Xu et al., "Genetic variants in microRNAs and their binding sites within gene $3^{\prime}$ UTRs associate with susceptibility to age-related macular degeneration," Human Mutation, vol. 38, no. 7, pp. 827-838, 2017.

[31] K. Hirota, H. Keino, M. Inoue, H. Ishida, and A. Hirakata, "Comparisons of microRNA expression profiles in vitreous humor between eyes with macular hole and eyes with proliferative diabetic retinopathy," Graefe's Archive for Clinical and Experimental Ophthalmology, vol. 253, no. 3, pp. 335-342, 2015.

[32] M. Nikpay, K. Beehler, A. Valsesia et al., "Genome-wide identification of circulating-miRNA expression quantitative trait loci reveals the role of several miRNAs in the regulation of cardiometabolic phenotypes," Cardiovascular Research, vol. 115, no. 11, pp. 1629-1645, 2019.

[33] I. F. Machado, J. S. Teodoro, C. M. Palmeira, and A. P. Rolo, "miR-378a: a new emerging microRNA in metabolism," Cellular and Molecular Life Sciences, vol. 77, no. 10, pp. 1947-1958, 2020.

[34] S. Niu, Y. Ni, T. Niu, and J. Gao, "Knockdown PEG10 deteriorates $\mathrm{H}_{2} \mathrm{O}_{2}$-injury of PC-12 cells by targeting miR-34a5p/TLX," Molecular Immunology, vol. 118, pp. 1-8, 2020.

[35] R. Dong, G. B. Liu, B. H. Liu et al., "Targeting long non-coding RNA-TUG1 inhibits tumor growth and angiogenesis in hepatoblastoma," Cell Death \& Disease, vol. 7, no. 6, article e2278, 2016.

[36] Z. He, X. Ruan, X. Liu et al., "FUS/circ_002136/miR-1385p/SOX13 feedback loop regulates angiogenesis in glioma," Journal of Experimental \& Clinical Cancer Research, vol. 38, no. 1, p. 65, 2019. 